\title{
Rheological properties of gelatine solutions for production of gluten-free pasta
}

\author{
Oleksandr Rozhno, Olena Podobiy, Vira Yurchak
}

\author{
National University of Food Technologies, Kyiv, Ukraine
}

Keywords:

Gelatine

Dosage

Viscosity

Solution

Quality

\section{Article history:}

Received 22.02.2016

Received in revised

form 19.04.2016

Accepted 30.06.2016

\section{Corresponding author:}

Olena Podobiy

E-mail:

e.podoby@yandex.ua

\section{Abstract}

Introduction. For formation of gluten-free pasta products of corn meal that does not form gluten, the selection of a structure forming substance, determining the way of its introduction and dosage on the basis of the research of the rheological properties of its solutions and impact on the quality of the goods are important.

Materials and methods. The rheological properties of colloid gelatine solutions with the concentration of $0,50-1,25 \%$, which are prepared at the water temperature of $20^{\circ} \mathrm{C}$ and $40{ }^{\circ} \mathrm{C}$ and the swelling duration of $40 \mathrm{~min}$ and at $60{ }^{\circ} \mathrm{C}$ without the swelling are examined. The viscosity of these solutions is determined by the Reotest-2 viscometer at the temperature of $20^{\circ} \mathrm{C}$. According to the data obtained, the rheological viscosity and fluidity curves are built and the rheological properties of the solutions are calculated. The impact of the forming substance solutions on the quality indicators of pasta products is determined.

Results and discussion. At the gelatine swelling temperature of $20^{\circ} \mathrm{C}$, the dynamic viscosity of the undistorted structure of the colloid solution decreases from $59,10 \mathrm{~Pa} \cdot \mathrm{s}$ to $21,89 \mathrm{~Pa} \cdot \mathrm{s}$ as its concentration increases from $0,50 \%$ to $1,25 \%$, except for the solution with the concentration of $1,00 \%$, for which the viscosity abnormality is noticed, and its viscosity is equal to $531,90 \mathrm{~Pa} \cdot \mathrm{s}$. The similar research carried out at swelling at the water temperature of $40{ }^{\circ} \mathrm{C}$ showed that all colloid gelatine solutions are pseudoplastic liquids $\left(\mathrm{P}_{\kappa} 1=0\right)$ at the concentration of $0,50-1,25 \%$ and have much lower dynamic viscosity for both the distorted and undistorted structure and lower strength of the structural frame than the same at the swelling temperature of $20^{\circ} \mathrm{C}$. For the sample with the concentration of $0,75 \%$, the viscosity abnormality is noticed: at such concentration, the solution has the greatest dynamic viscosity of the undistorted structure, the greatest dynamic viscosity of distorted structure, 94,56 and 1,35 $\mathrm{Pa} \cdot \mathrm{s}$ respectively, the greatest value of $\eta_{0}-\eta_{\mathrm{m}}, 93,21 \mathrm{~Pa} \cdot \mathrm{s}$, and at the same time, the greatest strength of 425,52 $\mathrm{Pa}$ of the formed structural frame. The pasta products manufactured with the use of such solutions are of the best quality. At the temperature of $60{ }^{\circ} \mathrm{C}$, the solutions have low viscosity and strength, thus forming weak gels that do not provide the formation of a solid structural frame and good quality of pasta products.

Conclusion. The gelatine dosage of $0,75-1,0 \%$ of the meal mass and the parameters of its preparation for production such as swelling in course of $40 \mathrm{~min}$ at the temperature of $40-20{ }^{\circ} \mathrm{C}$ respectively, which provide the highest viscosity of gelatine solutions of $94,6-531,9 \mathrm{~Pa} \cdot \mathrm{s}$ and facilitate the derivation of good-quality products, have been established. 


\section{- Food technologies_—}

\section{Introduction}

Over the last twenty years, the assortment of products in the pasta industry has narrowed dramatically. In particular, the products with enhanced nutritive value and those intended for health improvement and dietary purpose virtually are not produced.

Meanwhile, the number of metabolic diseases involving protein substances such as phenylketonuria and celiac disease among the population is growing. Prevention and treatment of these diseases consist in a special diet. For patients with celiac disease, products containing gluten are excluded from the food ration [13]. The food ration for the patients is very limited, so the promising line of diversification of the dietary pasta products assortment is production of gluten-free products [14, 15]. On the market of Ukraine, there are an insignificant number of non-domestic products for celiac disease patients [12]. The development of gluten-free pasta technology will facilitate providing the Ukraine's population with high-quality domestic products.

The raw substance for production of gluten-free pasta products is the by-products derived from corn, rice, buckwheat. The use of corn meal also provides an opportunity to create new products with enhanced chemical composition by means of their enrichment with the substances that are essential for the organism such as polyunsaturated fatty acids, fibre, $\beta$-carotene, iron and so forth.

Owing to the fact that corn meal does not form gluten that is of technological importance and is a principal structure forming substance in dough, the essential condition for creation of the gluten-free pasta products is the use of structure forming substances that may function in lieu of gluten.

Structure forming substances of various origins have different structure and therefore manifest themselves in different ways in the process of production of food products. Protein additives of both the plant and animal origins are used traditionally for enrichment of pasta products. Protein products of animal origin have the most valuable and balanced amino acid composition. References [1] include the information on the use of dry egg albumen and gelatine for enhancement of the quality and increasing the biological value of pasta products of wheat meal. It is expedient to examine the opportunity to use gelatine as a structure forming substance for production of gluten-free products of corn meal. This structure forming substance is a food product that is relatively cheap and widely presented on the market.

Gelatine is a protein product obtained by acid and alkaline hydrolysis of the connective tissues of the animal raw substance with the following extraction with hot water $[2,3,6]$. The key property of gelatine is the ability to form jelly in water solutions. This ability is caused by the asymmetry of high-polymer chains that are formed by the gelatine solution $[5,11]$. The more the asymmetry, the easier is the formation of a reticulate spatial frame of jelly, within the frame grid of which the water is contained.

There is a strict relation of solution viscosity, thickening and melting temperature with the molecular mass of gelatine and size of high-polymer chains [3, 7]. The lesser the molecular mass of gelatine, the lower the physical and chemical characteristics of its solutions.

The research of rheological properties of gelatine solutions and their impact on the quality of pasta products of corn meal will make it available to substantiate the parameters for the technological process of pasta products manufacturing and explain the mechanism of action of gelatine as a structure forming substance in dough. 


\section{Materials and methods}

The rheological characteristics of colloid gelatine solutions and their impact on the quality of gluten-free pasta products have been examined. The corn meal of fine grinding and fast-soluble food gelatine are used as basic raw substances for pasta products manufacturing.

Colloid gelatine solutions are prepared with the concentration of $0,50-1,25 \%$ of the portion of water intended for preparation of dough at the water temperature of $20^{\circ} \mathrm{C}, 40^{\circ} \mathrm{C}$ and swelling duration of $40 \mathrm{~min}$, and $60^{\circ} \mathrm{C}$ without swelling. The remainder of the water required for mixing is introduced directly into the dough at the temperature of $60{ }^{\circ} \mathrm{C}$. The gelatine dosage in the amount of $0,50-1,25 \%$ of the wheat mass is selected subject to the manufacturers' guidelines with regard to production of jelly products. The examination of rheological characteristics of these solutions is performed with the Reotest-2 viscometer at the temperature of $20^{\circ} \mathrm{C}$. The curves of system viscosity and fluidity are built according to the results obtained. At the treatment of the curves, the following viscosity and strength characteristics are calculated: dynamic viscosity of the undistorted structure $\left(\eta_{0}, \mathrm{~Pa} \cdot \mathrm{s}\right)$, dynamic viscosity of distorted structure $\left(\eta_{\mathrm{m}}, \mathrm{Pa} \cdot \mathrm{s}\right)$, viscosity abnormality value $\left(\eta_{0}-\eta_{\mathrm{m}}\right.$, $\mathrm{Pa} \cdot \mathrm{s}$ ), static limit of the system's flowing ability, (Рк1, Pa), dynamic limit of the system's flowing ability (Рк2, Pa), strength of the structural frame formed (Pm, Pa), strength of structural relations (Рк1/Рк2), range of stress (Рm/Рк1). The nature of the structure formed (pseudoplastic fluid, structured solid-like body, Newtonian fluid, thixotropic solid-like body, etc.) is determined according to the fluidity curves.

For examination of the impact of colloid gelatine solutions on the quality of pasta products, the dough is mixed in the laboratory press MAKMA-M with the mass fraction of moisture of $36 \%$, the mixing duration is equal to $10 \mathrm{~min}$. The pasta products are formed as noodles, dried to the moisture of $13,0-13,5 \%$ at the room temperature.

The quality indicators of pasta products such as surface condition, colour, microcracks availability, fracture condition, taste, smell, strength, acidity and cooking properties (mass $(\mathrm{Km})$ and volume gain $(\mathrm{Kv})$ coefficients, transition of dry substances into cooking water) are determined. The strength of the pasta is measured in Newtons $(\mathrm{N})$.

\section{Results and discussion}

The experimental data analysis (Table 1) shows that, at the gelatine swelling temperature of $20^{\circ} \mathrm{C}$, the dynamic viscosity of the undistorted structure of the colloid solution decreases from 59,10 $\mathrm{Pa} \cdot \mathrm{s}$ to $21,89 \mathrm{~Pa} \cdot \mathrm{s}$ as its concentration increases from $0,50 \%$ to $1,25 \%$, except for the solution with the concentration of $1,00 \%$, for which the viscosity abnormality is noticed, and its viscosity is equal to $531,90 \mathrm{~Pa} \cdot \mathrm{s}$. The dynamic viscosity of the distorted structure of these colloid solutions is much lesser, 0,72-6,23 $\mathrm{Pa} \cdot \mathrm{s}$, and it grows with the increase of gelatine concentration within the examined range.

Value $\mathrm{PK}_{1}$ shows that the colloid gelatine solution, at the concentration of $0,50 \%$, is a pseudoplastic fluid $\left(\mathrm{PK}_{1}=0\right)$, and a structured solid-like body at greater concentration $\left(\mathrm{PK}_{1}\right.$ $>0$ ). As the gelatine concentration within the examined range increases, the dynamic limit of the system's flowing ability significantly grows (from 166,97 Pa to $1899,04 \mathrm{~Pa}$ ) and so does the strength of the formed structural frame (from 236,40 Pa to 2364,00 Pa). Indicator $\mathrm{PK}_{1} / \mathrm{PK}_{2}$ characterising the strength of structural relations within the system is the highest for the solution with the gelatine concentration of $1,00 \%$, for which the viscosity abnormality is noticed. 
Table 1

Rheological characteristics of the gelatine solutions with the concentration of $0,50-1,25 \%$ in relation to the swelling (dissolution) temperature

\begin{tabular}{|l|r|r|r|r|r|r|r|r|}
\hline \multirow{2}{*}{} & \multicolumn{8}{|c|}{ Rheological characteristics of colloid solutions } \\
\cline { 2 - 11 } & & & & & & \\
\hline
\end{tabular}

Consequently, at the swelling temperature of $20{ }^{\circ} \mathrm{C}$, the viscosity abnormality for the gelatine solution takes place at its concentration of $1,00 \%$, and the highest viscosity value and quite high value of the system structure strength are achieved, which are determined by the high strength of structural relations. It is likely that such rheological properties of the solution of the structure forming substance may provide optimal structural and mechanical characteristics of dough and high quality of products. It is known [5] that the best quality of pasta products is achieved at the highest plasticity and strength of dough.

The similar research carried out at swelling at the water temperature of $40{ }^{\circ} \mathrm{C}$ showed that all colloid gelatine solutions are pseudoplastic liquids $\left(\mathrm{P \kappa}_{1}=0\right)$ at the concentration of $0,50-1,25 \%$ and have much lower dynamic viscosity for both the distorted and undistorted structure and lower strength of the structural frame than the same at the swelling temperature of $20^{\circ} \mathrm{C}$. At that, as the gelatine concentration increases, the dynamic viscosity of the solution and the strength of the formed structural frame decreases for both undistorted and distorted systems. It is evident that, at the temperature of $40{ }^{\circ} \mathrm{C}$, the partial dissolution of gelatine and decrease of the strength of structural relations take place, which is evidenced by value $\mathrm{P}_{\mathrm{k} 1} / \mathrm{P}_{\mathrm{k} 2}$. However, for the sample with the concentration of $0,75 \%$, the viscosity abnormality is noticed: at such concentration, the solution has the greatest dynamic viscosity of the undistorted structure, the greatest dynamic viscosity of distorted structure, 94,56 and 1,35 $\mathrm{Pa} \cdot \mathrm{s}$ respectively, the greatest value of $\eta_{0}-\eta_{\mathrm{m}}, 93,21 \mathrm{~Pa} \cdot \mathrm{s}$, and, at the same time, the greatest strength of $425,52 \mathrm{~Pa}$ of the formed structural frame.

Supposedly, the viscosity abnormality at the concentration of the solution of $0,75 \%$ may be explained by the fact that, at the water temperature of $35-40{ }^{\circ} \mathrm{C}$, gelatines 
act as unordered spirals that may take the infinite number of unsteady configurations, as the aggregation of the solution takes place at cooling. At the concentration of $1,00 \%$ and more, depending on the gelatine quality and its $\mathrm{pH}$, a colloid solution is formed, which is gel as for its structure. Authors $[4,8,9]$ consider the areas of gelatine chains which are rich of pyrrolidine to be a centre of formation of possible connective zones, where the collagenlike triple spiral is formed at the aggregation of these chains, which functions as the points or zones of gel formation. These zones are stabilized with the hydrogen links within the chain, which disintegrate at the temperature of $35-40{ }^{\circ} \mathrm{C}$ due to the thermolability at the concentration of gelatine of $1,00 \%$ and more, which causes the melting of gel. It is evident that, at the concentration of the colloid gelatine solution of $0,75 \%$, gel does not melt yet and to a greatest extent manifests the properties of a structure forming substance.

For the fast-soluble gelatine, it is recommended by the manufacturer that the dissolution temperature be $60{ }^{\circ} \mathrm{C}$, therefore the solution is not held at such temperature for swelling. The relation of the dynamic viscosity of the solution with the shear stress is given in Figure 1, and Table 1 data shows almost complete dissolution of gelatine: the dynamic viscosity of undistorted and distorted structure is very low and slightly changes as the concentration of the solution increases, and it is equal to $\eta_{0}-0,16-0,54, \eta_{m}-0,05-0,12$ $\mathrm{Pa} \cdot \mathrm{s}$ respectively. The solutions are pseudoplastic liquids, which are characterised by the low strength of the structural frame and structural relations.

As it is known [4, 10], in the gelatine gel held at a high temperature, a few collagenlike chains are formed and the remainder of each polypeptide chain interrupts the order, which entails the formation of weak gels. It is evident that the weak gels formed cannot fully prove to be structure-forming substances for pasta products.

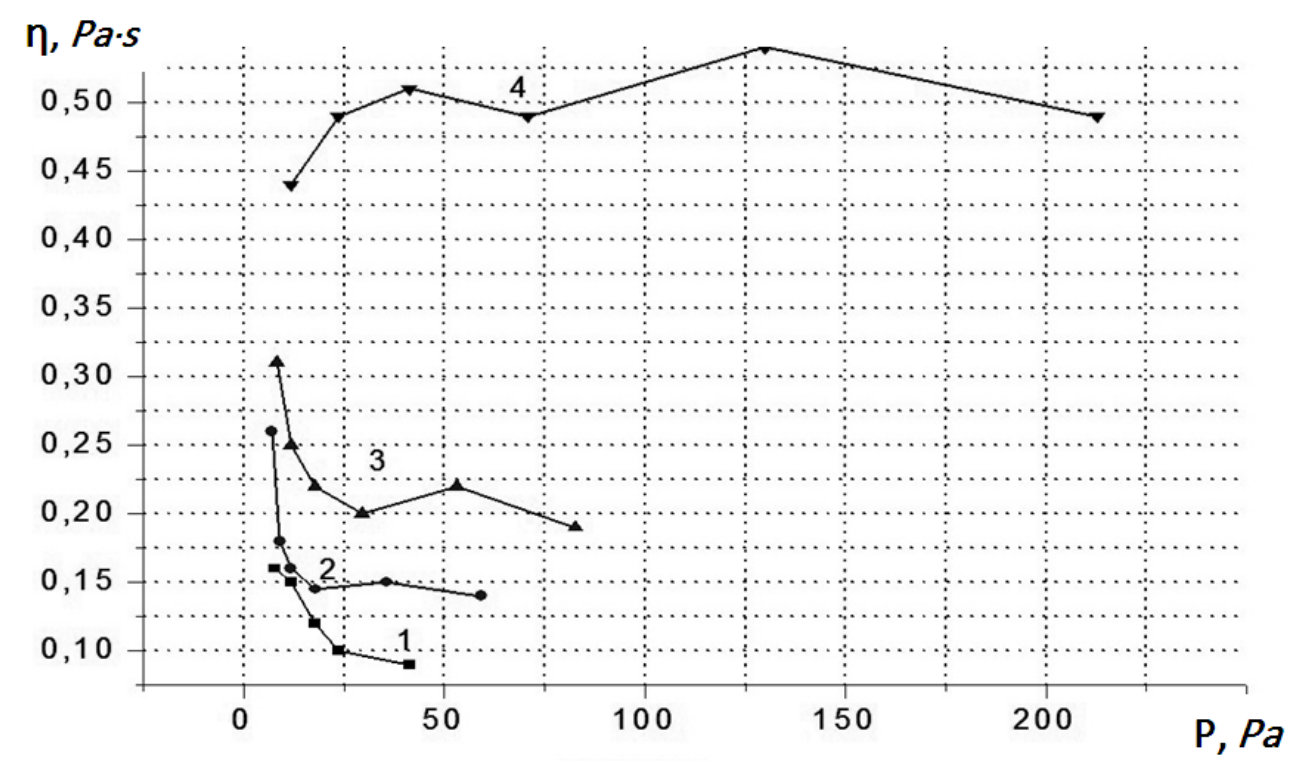

Fig. 1. Curves of the dynamic viscosity relation of the colloid gelatine solution at the water temperature of $60{ }^{\circ} \mathrm{C}(\eta)$ with the shear stress $(\mathrm{P})$ :

$1-c=0,5 \% ; 2-c=0,75 \% ; 3-c=1,00 \% ; 4-c=1,25 \%$ 


\section{- Food technologies_—}

The results of the analysis of the quality indicators of the products manufactured with the use of the gelatine solution obtained at the swelling temperature of $20{ }^{\circ} \mathrm{C}$ are presented in Table 2.

Table 2

Quality indicators of gluten-free pasta products of corn meal with the gelatine solution prepared at the water temperature of $20^{\circ} \mathrm{C}$

\begin{tabular}{|l|c|c|c|c|}
\hline \multirow{2}{*}{ Indicators } & \multicolumn{3}{c|}{ Products with gelatine dosage\% } \\
\cline { 2 - 5 } & $\mathbf{0 , 5 0}$ & $\mathbf{0 , 7 5}$ & $\mathbf{1 , 0 0}$ & $\mathbf{1 , 2 5}$ \\
\hline Surface & Organoleptic indicators \\
\hline Colour & \multicolumn{3}{|c|}{ creamy } & \multicolumn{2}{c|}{ light yellow } \\
\hline Fracture & mealy & $\begin{array}{c}\text { slightly } \\
\text { mealy }\end{array}$ & \multicolumn{2}{c|}{ glassy } \\
\hline Microcracks availability & \multicolumn{4}{|c|}{ solitary } \\
\hline Smell & \multicolumn{4}{|c|}{ peculiar to corn meal } \\
\hline Taste & \multicolumn{4}{|c|}{ peculiar to corn meal } \\
\hline \multicolumn{5}{|c|}{ Physical and chemical indicators } \\
\hline Acidity, degrees & 3,4 & 3,2 & 3,4 & 3,4 \\
\hline Strength, N & 5,8 & 5,9 & 6,9 & 6,3 \\
\hline \multicolumn{5}{|c|}{ Cooking properties } \\
\hline Form preservation & lost & retained, products do not stick together \\
\hline Mass gain coefficient, Km & 1,7 & 1,7 & 1,8 & 1,6 \\
\hline Volume gain coefficient, KV & 1,6 & 1,8 & 1,8 & 1,7 \\
\hline $\begin{array}{l}\text { Transition of dry substances } \\
\text { into cooking water, \% of DS }\end{array}$ & 28,5 & 23,2 & 21,1 & 22,8 \\
\hline
\end{tabular}

It is established that the quality of products as for organoleptic indicators, strength and cooking properties improves as the dosage of gelatine increases. All samples, except for the products with the use of $0,50 \%$ of gelatine, have acceptable quality, however, the sample of pasta products of corn meal with the gelatine dosage of $1.00 \%$ is of the best quality. In terms of its organoleptic quality properties, this sample is distinguished from others by its light yellow colour, smooth surface, glassy fracture, high strength of $6,9 \mathrm{~N}$ and the lowest transition of dry substances into cooking water, $21,1 \%$ of dry substances. This particular dosage provides the highest rheological characteristics of the solution. Gaining the dosage over $1,00 \%$ also provides relatively good product quality, but it is still lower.

The quality indicators of gluten-free corn meal pasta products manufactured with the use of the colloid gelatine solution at the swelling temperature of $40{ }^{\circ} \mathrm{C}$ are presented in Table 3.

The data obtained shows that, at such temperature of gelatine preparation for production, the product quality is slightly lower compared to the use of the solution obtained at the swelling temperature of $20{ }^{\circ} \mathrm{C}$, except for the sample with the gelatine dosage of $0,50 \%$. The product strength, transition of dry substances into cooking water and the coefficients of mass and volume gain at the time of boiling are reduced. However, the best product quality is achieved at the dosage of $0,75 \%$. This sample has the light yellow colour, slightly rough surface, glassy fracture, a bit higher strength, 4,8 N, and the lowest 
percentage of transition of dry substances into cooking water, $22,2 \%$ of dry substances. At this particular dosage of the solution, the viscosity abnormality of the colloid solution and the highest values of viscosity and strength of its structural frame are noticed.

Table 3

Quality indicators of gluten-free corn meal pasta products with the colloid gelatine solution at the water temperature of $40{ }^{\circ} \mathrm{C}$

\begin{tabular}{|c|c|c|c|c|}
\hline \multirow[b]{2}{*}{ Indicators } & \multicolumn{4}{|c|}{ Products with the dosage of gelatine, $\%$} \\
\hline & $\mathbf{0 , 5 0}$ & 0,75 & 1,00 & 1,25 \\
\hline \multicolumn{5}{|c|}{ Organoleptic indicators } \\
\hline Surface & rough & & nooth & $\begin{array}{l}\text { slightly } \\
\text { rough }\end{array}$ \\
\hline Colour & creamy & \multicolumn{3}{|c|}{ light yellow } \\
\hline Fracture & mealy & glassy & slightly mealy & glassy \\
\hline Microcracks availability & available & absent & \multicolumn{2}{|c|}{ solitary } \\
\hline Taste & \multicolumn{4}{|c|}{ peculiar to corn meal } \\
\hline \multicolumn{5}{|c|}{ Physical and chemical characteristics } \\
\hline Acidity, degrees & 2,8 & 2,6 & 2,8 & 3 \\
\hline Strength, N & 4,3 & 4,8 & 4,6 & 4,5 \\
\hline \multicolumn{5}{|c|}{ Cooking properties } \\
\hline Form preservation & \multicolumn{4}{|c|}{ retained, products do not stick together } \\
\hline Mass gain coefficient, $\mathrm{Km}$ & 1,5 & 1,6 & 1,7 & 1,6 \\
\hline Volume gain coefficient, $\mathrm{Kv}$ & 1,6 & 1,7 & 1,7 & 1,7 \\
\hline $\begin{array}{l}\text { Transition of dry substances into } \\
\text { cooking water, } \% \text { of DS }\end{array}$ & 24,3 & 22,2 & 23,6 & 23,6 \\
\hline
\end{tabular}

The quality indicators of the gluten-free corn meal pasta products manufactured with the use of the gelatine solution obtained at the water temperature of $60{ }^{\circ} \mathrm{C}$ are presented in Table 4.

It has been established that, in this case, the quality of pasta products as for the indicators of glassiness and strength is almost on par with such of the products manufactured with the use of the gelatine solution obtained at the swelling temperature of $40{ }^{\circ} \mathrm{C}$. However, in terms of the cooking properties such as transition of dry substances into cooking water, product mass and volume gain coefficients, they are much worse and have unacceptable quality as for the indicator of transition of dry substances into cooking water, nearly $25 \%$ of DR and higher.

Consequently, basing on the results of the examination of the rheological characteristics of colloid gelatine solutions with the concentration of $0,50-1,25 \%$ at the water temperature of $20^{\circ} \mathrm{C}, 40{ }^{\circ} \mathrm{C}$ and $60{ }^{\circ} \mathrm{C}$, it has been proven that the best quality of pasta products of corn meal is achieved at the gelatine dosage of $0,75-1,00 \%$ of the mass of meal and the parameters of its preparation for production such as swelling in course of 40 min at the temperature of $40-20{ }^{\circ} \mathrm{C}$ respectively, which provide the highest viscosity of gelatine solutions, 94,6-531,9 $\mathrm{Pa} \cdot \mathrm{s}$. The pasta product quality deteriorates as the solution viscosity decreases. 
Table 4

Quality indicators of gluten-free corn meal pasta products with the colloid gelatine solution at the water temperature of $60^{\circ} \mathrm{C}$

\begin{tabular}{|c|c|c|c|c|}
\hline \multirow[b]{2}{*}{ Indicators } & \multicolumn{4}{|c|}{ Products with the dosage of gelatine, $\%$} \\
\hline & $\mathbf{0 , 5 0}$ & 0,75 & $\mathbf{1 , 0 0}$ & $\mathbf{1 , 2 5}$ \\
\hline \multicolumn{5}{|c|}{ Organoleptic indicators } \\
\hline Surface & rough & slightly rough & smooth & slightly rough \\
\hline Colour & creamy & \multicolumn{3}{|c|}{ light yellow } \\
\hline Fracture & \multicolumn{4}{|c|}{ glassy } \\
\hline Microcracks availability & solitary & \multicolumn{3}{|c|}{ absent } \\
\hline Taste & \multicolumn{4}{|c|}{ peculiar to corn meal } \\
\hline Colour & \multicolumn{4}{|c|}{ peculiar to corn meal } \\
\hline \multicolumn{5}{|c|}{ Physical and chemical characteristics } \\
\hline Acidity, degrees & 3,2 & 3 & 3,2 & 3,4 \\
\hline Strength, N & 4,2 & 4,4 & 4,5 & 4,6 \\
\hline \multicolumn{5}{|c|}{ Cooking properties } \\
\hline Form preservation & \multicolumn{4}{|c|}{ retained, products do not stick together } \\
\hline Mass gain coefficient, $\mathrm{Km}$ & 1,6 & 1,5 & 1,5 & 1,5 \\
\hline Volume gain coefficient, $\mathrm{Kv}$ & 1,7 & 1,7 & 1,6 & 1,7 \\
\hline $\begin{array}{l}\text { Transition of dry substances } \\
\text { into cooking water, } \% \text { of DS }\end{array}$ & 28,8 & 25,9 & 24,5 & 24,8 \\
\hline
\end{tabular}

\section{Conclusions}

Basing on the conducted research, the structure forming ability of gelatine and feasibility of its use for the formation of gluten-free pasta products of corn meal that does not contain gluten has been proven.

It has been established that the viscosity of gelatine solutions is reduced with an increase in the swelling temperature up to $40^{\circ} \mathrm{C}$ by virtue of partial dissolution of gelatine, and that their viscosity is significantly reduced at the water temperature of $60^{\circ} \mathrm{C}$.

It has been established that, at the gelatine swelling temperature of $20^{\circ} \mathrm{C}$, the viscosity abnormality of the solutions with the concentration of $1,00 \%$ takes place, and that is the case at the temperature of $40{ }^{\circ} \mathrm{C}$ with the concentration of $0,75 \%$. The viscosity of these solutions is equal to $531,9 \mathrm{~Pa} \cdot \mathrm{s}$ and $94,56 \mathrm{~Pa} \cdot \mathrm{s}$ respectively.

It has been established that the best quality of the pasta products of corn meal is achieved with adding $1,00 \%$ of gelatine to the meal mass in a form of a colloid solution at the water temperature of $20{ }^{\circ} \mathrm{C}$. At the temperature of $40{ }^{\circ} \mathrm{C}$, the pasta products with the dosage of gelatine of $0,75 \%$ are of the best quality. At the temperature of $60{ }^{\circ} \mathrm{C}$, the dissolution of gelatine takes place, and there are weak gels formed, which cannot prove to be structure forming substances.

Upon the rheological research results, the optimal viscosity range of the colloid gelatine solutions has been initially established for production of gluten-free corn meal pasta products of good quality, and it is 94,6 up to $531,9 \mathrm{~Pa} \cdot \mathrm{s}$. 


\section{References}

1. Yevseienko T. P., Yurchak V. H. (2004), Stvorennia makaronnykh vyrobiv z sukhym yaiechnym bilkom dlia bilkovoho zbahachennia ratsioniv kharchuvannia, Problemy kharchuvannia, 4 (4), pp. 42-46.

2. Alan Imeson (Ed.) (2009), Food Stabilisers, Thickeners and Gelling Agents, Wiley-Blackwell, Blackwell Publishing Ltd.

3. Pasychnyi V. N. (2005), Proyzvodstvo y prymenenye zhelatyna v pyshchevoi promishlennosty, Produkty y ynhredyenty, 5(1), pp. 10-14.

4. Glyn O. Phillips, Peter A. Williams (2009), Handbook of Hydrocolloids (2nd Edition), Woodhead Publ Ltd, New York.

5. Medvedev H.M. (2006) Tekhnolohiya makaronnykh izdelii, Hiord, Sankt-Peterburg.

6. Guedj S. (2005), Crosslinks and Their Role in the Chemistry of Gelatine, IAG Conference, Heidelberg.

7. Cuvelier G., Michon C. (2003), Gelatine Substitution: What Functionalities? Rennes: Polymerix, pp.1-9.

8. de Wolf F. A. (2003), Collagen and gelatin, Industrial Proteins in Perspective, Chapter $\mathrm{V}$, Elsevier Sciences, 23, pp. 133-218.

9. Jones B. E. (2004), Gelatine: manufacture and physic-chemical properties, Pharmaceutical Capsules 2nd ed., Ch. 2, Pharmaceutical Press, London, pp. 23-60.

10. Liang H. C. (2004), Crosslinking structures of gelatine hydrogels crosslinked with genipin or a water-soluble carbodiimide, J. of Applied Polymer Science, 91, pp. 4017-4026.

11. Ward A. (2007), The Science and Technology of Gelatine, Academic Press, London.

12. Menrad K. (2003), Market and Marketing of Functional Food in Europe, Journal of Food Engineering, 56(2-3), pp. 181-188.

13. Kagnoff M. (2005), Overview and pathogenesis of celiac disease, Gastroenterology, 128 , pp. 10-18.

14. Gallagher E. (2009), Gluten-free Food Science and Technology, Wiley-Blackwell, pp. 5-6.

15. Fasano A., Catassi C. (2001) Current approaches to diagnosis and treatment of celiac disease: an evolving spectrum, Gastroenterology, 120, pp. 636-651. 